\title{
Perioperative nursing - exclusive or inclusive?
}

Follow this and additional works at: https://www.journal.acorn.org.au/jpn

Part of the Perioperative, Operating Room and Surgical Nursing Commons

\section{(c) (i)}

This work is licensed under a Creative Commons Attribution 4.0 License.

\section{Recommended Citation}

Williams, Carollyn (2022) "Perioperative nursing - exclusive or inclusive?," Journal of Perioperative Nursing: Vol. 35 : Iss. 1 , Article 2.

Available at: https://doi.org/10.26550/2209-1092.1180

https://www.journal.acorn.org.au/jpn/vol35/iss1/2

This Editorial is brought to you for free and open access by Journal of Perioperative Nursing. It has been accepted for inclusion in Journal of Perioperative Nursing by an authorized editor of Journal of Perioperative Nursing. 


\section{Author}

Carollyn Williams

M Hlth SC (Nur), FACORN, FACN

ACORN Excellence in Perioperative

Nursing Award 2008

ACORN Board 2010-2014

ACORN Censor Panel (Chair 2010-2016;

Member 2018-present)

Judith Cornell Orator 2016

\section{Perioperative nursing - exclusive or inclusive?}

\section{Introduction}

Perioperative nursing is my specialty area of practice. My practice has included instrument and circulating nurse, unit manager, surgeons' assistant and predominantly education in both hospital and tertiary settings. While working for surgeons I was an instrument nurse, practice nurse and surgeon's assistant. I have experienced, and thus believe, that perioperative practice is about the comprehensive care of patients during their entire perioperative journey.

The term 'perioperative' evolved from the terms used for the work of nurses in operating rooms and operating suites. The prefix 'peri' was used to convey the concept that operating room nurses undertook more than just the intraoperative role - they were involved in the pre-operative, intra-operative and post-operative phases of the patient's surgical experience. Thus was established a framework which allowed an expansion of, and a vision for, the future practice of perioperative nurses with the development of standards for practice and postgraduate education for perioperative practice.

However, perioperative nursing is very much a multidimensional area of practice that has evolved as models of perioperative patient care, surgery, anaesthetics and their complexity, techniques and equipment have evolved. Within the broad perioperative area there are numerous nursing roles. However, they do not all necessarily identify as being under a singular 'perioperative' umbrella and this is largely due to how the roles evolved. Thus the question: is perioperative nursing exclusive, in that it identifies with only one facet of the pre-operative, intra-operative and post-operative phases of the patient's surgical experience? Or is it inclusive, in that nurses who work in any of these phases consider themselves perioperative nurses with a common aim to advance safe, quality perioperative nursing care for Australians?

\section{Evolution}

Perioperative nursing roles have evolved from the original instrument and circulating nurses to comprise anaesthesia nurses, post-anaesthesia nurses, day surgery/procedure nurses, nurse surgical assistants, pre-admission nurses and nurse practitioners. Awareness of the need for anaesthesia nurses evolved as the complexity of anaesthetic procedures and equipment developed. The establishment of Post Anaesthesia Care Units (PACUs) began after World War II to safely provide more critical post-operative care. With the evolution of surgical and anaesthetic techniques, post-operative care became more complex.

In the 1980s, when new models of surgical patient care were introduced, day surgery/procedure centres were established. Perioperative nurses undertook expanded roles in these settings of pre-operative assessment and patient education, and postoperative education and discharge planning.

A further advancement of day surgery in the 1990s was day-of-surgeryadmission (DOSA) for all types of surgery, major and minor, and the establishment of pre-admission clinics. These clinics are nurse led and have a close collaborative 
relationship with operating suite staff; they have also resulted in more extended roles for perioperative nurses. Also in the 1990s, another extension of the perioperative role was that of assistant to the surgeon or perioperative nurse surgeon's assistant (PNSA). With the evolution of the nurse practitioner in Australia, PNSAs and other perioperative nurses have been able to extend their advanced practice and become nurse practitioners (NPS).

\section{Consequences of the evolution process}

The roles of nurses evolved and expanded at different rates and with different focuses, and professional organisations representing these roles developed separately. Following World War II, operating room nurses formed professional organisations to address the future growth and development of operating room nursing as a specialty. Australian organisations were formed state by state; the first in 1956 in New South Wales, followed by the other states over the next two decades. In 1977 the Australian Confederation of Operating Room Nurses (ACORN) was formed as the national body representing all the state and territory organisations. ACORN became a College in 2000 and is now the Australian College of Perioperative Nurses.

The Victorian Society of Post Anaesthetic and Anaesthetic Nurses group (VSPAAN) was founded in 1994 to "provide education for perianaesthesia nurses, as other special interest groups were not addressing their perianaesthesia needs'. In 2005, as it's national membership grew, VSPAAN changed its name to Australian Society of Post Anaesthetic and Anaesthetic Nurses (ASPAAN) and in 2016 ASPAAN became the Australian College of Perianaesthesia Nurses (ACPAN).
The Australian Day Surgery Nurses Association (ADSNA) was formed in 1995 as an association of the day surgery special interest groups in Victoria, New South Wales, South Australia and Western Australia. The Pre-admission Nurses Association (PaNA) was established in 2001, as a result of the increase in preadmission services across Victoria. It is a special interest group of the Australian Nursing and Midwifery Federation (ANMF).

The first cohort of eight perioperative nurse surgeon's assistant (PNSA) students graduated from Southern Cross University in 2001. The Australian Association of Nurse Surgical Assistants was formed in 2011 with the purpose of obtaining recognition for the PNSA role. The Australian College of Nurse Practitioners (ACNP) came into being in 2010 following the growth of NP roles across Australia.

\section{A vision}

Perioperative nursing roles are currently represented by five separate national professional organisations. Of these ACORN and ADSNA are federations of state and territory organisations.

From the Australian Institute of Health and Welfare 2016 report into nursing and midwifery, which uses data from 2015, there were over 24351 registered nurses working in perioperative nursing - approximately 9.51 per cent of the registered nurse workforce. ${ }^{3}$ Today there are over 5000 members of ACORN. This represents approximately 23 per cent of the perioperative workforce. ACPAN has more than 700 members, AANSA has over 100 members and PaNA also has over 100 members.

At the first Australasian Conference of Operating Room Nurses, held in 1977, the perioperative nursing leaders of the time had a vision of a national organisation that would provide strong professional leadership for perioperative nurses. Judith Cornell AM (1940-2014), who was the chair of the committee that organised the conference, was a leader who understood 'the need for solidarity and cohesion between nursing organisations.', p,6 While Judith's comment then applied to the wider nursing community, it can now be applied to perioperative nursing organisations.

If perioperative nursing is exclusive, as suggested by the evolution of multiple roles and the formation of five separate national professional organisations, then the overall strength of the perioperative nursing profession is significantly diminished. The amount of knowledge, skills, expertise and resources within the five separate organisations is substantial, and if perioperative nursing is inclusive then the peak professional bodies representing all the roles that sit under this umbrella should be working collaboratively together to sustain the professions strength and vitality for the future.

Inclusiveness will also promote more research activity. Professor Jed Duff has spoken of the disparity between perioperative research and that of other nursing specialties. Nursing research in emergency departments (EDs) and intensive care units (ICUs) has significantly increased over the past 20 years, whereas perioperative nursing research has remained static. In addition, ED and ICU research are generating four to five times more publications each year than research into perioperative nursing.

The ACORN strategic plan (2019-2022) provides guidance on how such alliances can achieve perioperative strength and vitality. That is by:

- establishing leadership through standard setting 
- providing a voice for perioperative nursing

- ensuring the health of the perioperative nursing profession

- building capacity and capability. ${ }^{6}$

The peak professional bodies representing nurses who care for patients during their perioperative journey must work together effectively to achieve the common aim of providing safe, quality, evidence-based care. They must communicate and collaborate on a macro level, and use their knowledge, skills and expertise to identify and act on issues. A summitlike model would focus activities and support research, standards, education, membership, stakeholder networking and consumer liaison. Such an approach can gain a seat at government tables and influence health policy. Just as the patient's perioperative journey is one single event, the peak perioperative professional bodies must adopt an inclusive approach, embrace unity and collaboration so the profession can speak with a single strong voice. This voice will raise the profile of perioperative nursing and sustain the profession's strength and vitality for the future.

When thinking about the separate national perioperative nursing professional organisations, I am reminded of the motto 'united we stand, divided we fall'. Its main premise is that unity and collaboration are more likely to meet with success than individualism. Although the phrase was coined by Aesop in the fable 'The four oxen and the lion', it equally applies to perioperative nurses facing the pressures of working in the current health care system.

\section{References}

1. Australian College of Perianaesthesia Nurses (ACPAN). About [Internet]. Melbourne: ACPAN; 2022 [cited 4 Jan 2022]. Available from acpan.edu.au/about

2. Australian Nursing and Midwifery Federation, Victorian Branch (ANMF Vic Branch). PreAdmission Nurses Association (Special Interest Group) [Internet]. Melbourne: ANMF Vic Branch; 2020 [cited 4 Jan 2022]. Available from www.anmfvic.asn.au/interest-groups/ pre-admission-nurses-association-sig

3. Australia Institute of Health and Welfare (AlHW). Nursing and midwifery workforce 2015 [Internet]. Canberra: AlHW; 2016 [cited 4 January 2022]. Available from www.aihw.gov.au/reports/workforce/ nursing-and-midwifery-workforce-2015/data

4. Chiarella, M. Preserving history. The Hive. 2016;29(Autumn):6.

5. Duff, J. The imperative to build research capacity and promote evidence based practice in Australian perioperative nurses. JPN. 2020 Dec 1 [cited 4 Jan 2022]; 33(2):e-3-e-4. DOI 10.26550/2209-1092.1100

6. Australian College of Perioperative Nurses (ACORN). (2020). Next phase of growth: Strategy and implementation plan 2019-2022 [Internet]. ACORN; 2019 [cited 4 Jan 2022]. Available from: www.acorn.org.au/client images/2148796.pdf 